\title{
Needle Stick and Sharp Injuries Among Healthcare Workers \\ A retrospective six-year study
}

"Rami Saadeh, ${ }^{1}$ Khaled Khairallah, ${ }_{1}^{1}$ Hussein Abozeid, ${ }^{2}$ Lama Al Rashdan, ${ }^{3}$ Mahmoud Alfaqih, ${ }^{4}$ Obaidallah Alkhatatbeh ${ }^{2}$

$$
\begin{aligned}
& \text { إصابات الإبر والأدوات الحادة لدى عمال الرعاية الصحية } \\
& \text { دراسة إستعادية لمدة ستة سنوات }
\end{aligned}
$$

رامي سعادة، خالد خير الله، حسين أبوزيد، لما الرشان، محمود الفقيه، عبيد الله الخطاطبة

ABSTRACT: Objectives: This study aimed to examine the proportion of needle stick and sharp injuries (NSSIs) among healthcare workers at King Hussein Medical Center (KHMC), Amman, Jordan. Methods: All NSSI reports referred from departments at KHMC to the Preventive Medicine Department between 2013-2018 were retrospectively reviewed. Proportion of NSSIs were calculated and stratified according to age, gender, job title, place and site of injury and the procedure/task during which the injury occurred. Results: There were a total of 393 NSSIs. A significant association was found between the proportion of NSSIs and all tested variables $(P<0.001)$. The reported proportion of NSSIs was highest among nurses (39.7\%) followed by cleaners (36.3\%), physicians (10.4\%), other workers $(7.4 \%)$ and lab technicians (5.9\%) during the study's six-year period. Hospital wards were the most common locations (46.1\%) where injuries took place. Injuries also occurred most frequently during medical waste collection (38.2\%). Conclusion: The proportion of NSSIs was highest among nurses and cleaners. Safety policies and training among high-risk groups should be reviewed to reduce the risk of NSSIs. Multicentre studies at a national level should be conducted to examine whether this study's findings reflect national trends.

Keywords: Needlestick Injuries; Safety; Self Report; Nurses; Accident Prevention; Jordan.

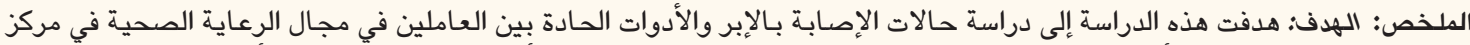

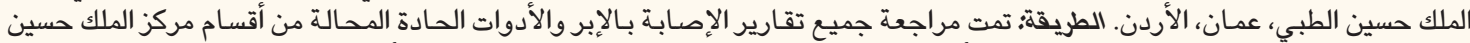

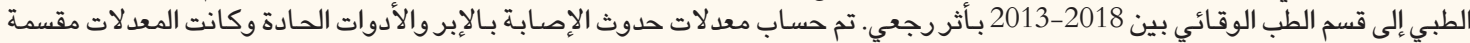

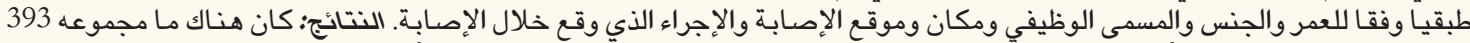

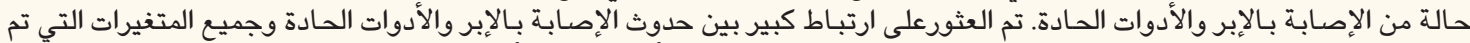

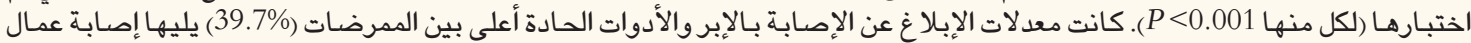

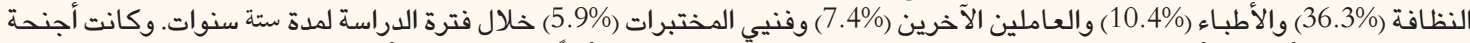

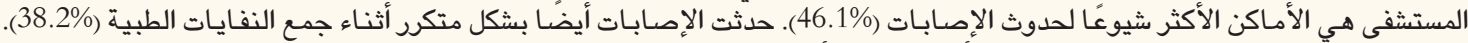

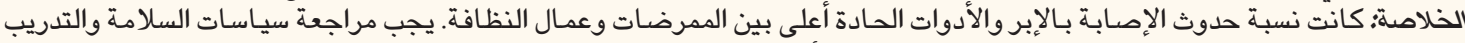

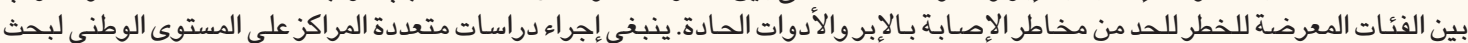
ما إذا كانت نتائج هذه الدراسة تعكس الاتجاهـات الوطن الإطنية.

$$
\text { الكلمات المفتاحية: إصابات الإبر؛ السلامة؛ تقرير ذاتي؛ الممرضين؛ الوقاية من الحوادث؛ الأردن. }
$$

\footnotetext{
AdVANCES IN KNOWLEDGE

The current study highlights work-related factors associated with needlestick and sharp injuries (NSSIs) in settings where a surveillance system does not exist.

This study highlights the importance of initiating effective surveillance as well as a reporting system that could contribute to reducing the occurrence of NSSIs locally and nationally.

Application to Patient Care

A safe work environment that minimises injuries among healthcare workers provides a higher level of quality care to patients and lower possibility of infectious disease transmission.
}

$\mathrm{P}$ ERCUTANEOUS NEEDLE STICK AND SHARP injuries (NSSIs) could be associated with healthcare workers' (HCWs) exposure to hepatitis B (HBV), hepatitis C (HCV) and HIV. More than 20 other infections could be transmitted through NSSIs, including syphilis, malaria and herpes. ${ }^{1,2}$ Using devices with safety features, promoting health education and implementing safety protocols and 
training programmes for individuals at risk of NSSIs are part of national public health policies designed to prevent the transmission of blood-borne pathogens among or to HCWs. ${ }^{3}$ Although most NSSIs occur in developing countries, NSSIs are still reported in developed countries, indicating that NSSIs might be a global problem. Indeed, although developed countries use prevention measures as advanced as real-time injury monitoring systems coupled with standard operating protocols, NSSIs still occur. ${ }^{4,5}$

The prevalence of NSSIs is higher in developing countries than developed countries. ${ }^{6}$ However, experiences from several developing countries demonstrate that implementing national health policy plans consisting of established safety protocols and offering mandatory training programmes to $\mathrm{HCWs}$ can be successful in reducing the prevalence of NSSIs and associated infections. ${ }^{7,8}$ Despite the established safety protocols in some developing countries, compliance with safety protocols is below expectations and NSSIs often go unreported. ${ }^{9,10}$ It has been suggested that to improve compliance with guidelines related to infection control practices, a culturally-oriented approach which aims to improve overall community awareness and focuses on both organisational and individual accountability should be developed. However, for this approach to be successful in achieving its goals, it must be supported by establishing policies and surveillance systems and providing adequate training to HCWs. ${ }^{11,12}$

Few studies have examined NSSIs in Jordan and most have only included data collected from practicing nurses or nursing students. ${ }^{10,13-15}$ These studies concluded that NSSI rates are high among nurses and nursing students, the level of awareness of universal precaution guidelines is low, reporting occupational exposures to NSSIs is inadequate and young female nurses with fewer years of experience are more vulnerable to NSSIs..$^{10,13-15}$ Studies on the proportion of NSSIs among HCWs, except nurses, have not been conducted in Jordan. Moreover, none of the studies investigated the practices and predisposing factors associated with NSSIs among affected HCWs. Thus, further investigations are needed to understand the causes of the high NSSI rate and the low level of knowledge of safety practices and precautionary guidelines. ${ }^{16,17}$ It is difficult to identify the precise reason for the high proportion of NSSIs; however, by collecting information about the site of injury, the hospital department where the injury took place and the procedure performed by the HCW when the NSSI occurred, it may be possible to infer trends. Identifying these trends would allow for the development of better preventive measures and programmes.

The lack of similar studies in Jordan and a shortage of addressing HCWs' safety concerns in public hospitals necessitates efficient, useful and accurate research which may yield possible prevention methods. Therefore, this study aimed to measure the proportion of NSSIs among HCWs of the Jordanian Royal Medical Services between 2013-2018, to examine the associations of selected factors, including age, gender, job, place and site of injury and type of procedure/task performed when the NSSI occurred.

\section{Methods}

This retrospective study was conducted at the Preventive Medicine Department at King Hussein Medical Center (KHMC), Amman, Jordan, between 2013-2018. The Preventive Medicine Department is the site of referral for all injuries from all other departments at KHMC and is thus expected to house all injury reports regardless of the department in which they took place.

$\mathrm{KHMC}$ is a medical compound consisting of five hospitals. This centre is one of the major Jordanian Royal Medical Services hospitals distributed in different governorates across Jordan. Injury report forms are housed within the Department of Preventive Medicine at the Royal Medical Services, which covers all HCWs.

All NSSI report sheets were collected and reviewed by a clinical research coordinator and all data used for analysis were extracted directly from the reports. All reported cases that took place between 2013-2018 were included in the study. Data collected included age, gender, job, place and site of injury and type of procedure/task being performed at the time of injury.

Extracted data were entered in Excel spreadsheets, Version 2010 (Microsoft Corp., Redmond, Washington, USA) and then exported into Statistical Package for the Social Sciences (SPSS), Version 22 (IBM, Corp., Armonk, New York, USA), which was used for all analyses. The proportion of NSSIs was calculated based on age, gender, job, place and site of injury and type of procedure when injury occurred. Chi-squared test was used to examine relationships among the above listed variables. A $P$ value $<0.05$ was considered statistically significant.

This study was approved by the Institutional Review Board Committee of KHMC. 
Table 1: Distribution of needle stick and sharp injuries according to selected variables of healthcare workers in Jordan $(\mathrm{N}=393)$

\begin{tabular}{|c|c|}
\hline Variable & n (\%) \\
\hline \multicolumn{2}{|l|}{ Age in years } \\
\hline$<20$ & $7(1.8)$ \\
\hline $20-30$ & $261(66.4)$ \\
\hline$>30$ & $125(31.8)$ \\
\hline \multicolumn{2}{|l|}{ Gender } \\
\hline Male & $218(55.5)$ \\
\hline Female & $175(44.5)$ \\
\hline \multicolumn{2}{|l|}{ Job title } \\
\hline Physician & $41(10.4)$ \\
\hline Nurse & $156(39.7)$ \\
\hline Lab technician & $23(5.9)$ \\
\hline Cleaner & $144 .(36.6)$ \\
\hline Other & $29(7.4)$ \\
\hline \multicolumn{2}{|l|}{ Place of injury } \\
\hline OR & $60(15.3)$ \\
\hline Laboratory & $27(6.9)$ \\
\hline Hospital wards & $181(46.1)$ \\
\hline OP clinic & $48(12.2)$ \\
\hline Other & 77 (19.6) \\
\hline \multicolumn{2}{|l|}{ Site of injury } \\
\hline Right hand & $166(42.2)$ \\
\hline Left hand & $192(48.9)$ \\
\hline Lower limb & $27(6.9)$ \\
\hline Chest \& abdomen & $2(0.5)$ \\
\hline Head \& neck & $6(1.5)$ \\
\hline \multicolumn{2}{|c|}{ Procedure/task during which injury occurred } \\
\hline Medical waste collection & $150(38.2)$ \\
\hline Giving medication & 41 (10.4) \\
\hline Blood sampling & $61(15.5)$ \\
\hline Surgical intervention & $59(15)$ \\
\hline Blood analysis & $24(6.1)$ \\
\hline Unusual occurrence & $58(14.8)$ \\
\hline \multicolumn{2}{|l|}{ Year injury reported } \\
\hline 2013 & $59(15.0)$ \\
\hline 2014 & $64(16.3)$ \\
\hline 2015 & $83(21.1)$ \\
\hline 2016 & 77 (19.6) \\
\hline 2017 & $57(14.5)$ \\
\hline 2018 & $53(13.5)$ \\
\hline
\end{tabular}

$O R=$ operating room; $O P=$ outpatient .

\section{Results}

A total of 393 NSSIs were included in this study. More than half of reported injuries were among males (55.5\%) and almost two-thirds were among those aged 20-30 years old (66.4\%). Most reported cases were among nurses (39.7\%) and cleaners (36.6\%). Almost half of reported injuries occurred in hospital wards (46.1\%) and more than one-third of reported injuries occurred during medical waste collection (38.2\%). Injuries occurred mainly in the left and right hand (48.9\% and $42.2 \%$, respectively). Although injury rates increased from $15.0 \%$ in 2013 to $21.1 \%$ in 2015 , they declined to $13.5 \%$ in 2018 [Table 1].

All variables were statistically significant according to participants' job titles ( $P<0.001$ each). Most injuries among those $20-30$ years old occurred among nurses (59.4\%) and cleaners (22.6\%). Among those older than 30 years, most injuries (68\%) were found among cleaners. The majority of reported injuries among males were from nurses (67.4\%) and among females, cleaners had the most injuries (66.9\%). Within laboratory settings, all cases were among nurses and in wards the majority (57.5\%) was found among nurses. In the outpatient (OP) clinics, almost all injuries were among cleaners (97.9\%). Right-hand injuries occurred mostly among nurses (68.7\%) while left-hand injuries were most common among cleaners (66.1\%). Although the incidence of NSSIs during medical waste collection or while giving medication was mainly among nurses, injuries during other procedures occurred most often among cleaners [Table 2].

The comparison of NSSIs by location of injury to all variables was statistically significant $(P<0.001$ each). In 20-30 years old, most NSSIs happened in hospital wards (67\%) followed by the operating room (OR; 20.3\%). Males reported having more in-ward injuries than females (60.1\% versus $28.6 \%$, respectively). Most injuries among physicians occurred in the OR (85.4\%) while injuries among nurses occurred mainly in wards (66.7\%), followed by the laboratory (17.3\%) and the OR (16\%). Right and left hand injuries were mainly reported in hospital wards $(47.6 \%$ and $53.1 \%$, respectively) [Table 3]. Following hospital wards (46.1\%), the most frequent place for injuries were other locations (19.6\%), ORs (15.3\%) and OP clinics (12.2\%) [Table 1].

All relationships between NSSIs by procedure and other independent variables were statistically significant $(P<0.001$ each). The proportion of NSSIs during medical waste collection was highest among those aged $20-30$ years (54.8\%) compared to other age groups. Females were more commonly injured during an unusual occurrence (33.1\%) or surgical intervention 
Table 2: Comparison of needle stick and sharp injuries by job title to independent variables of healthcare workers in Jordan $(\mathrm{N}=393)$

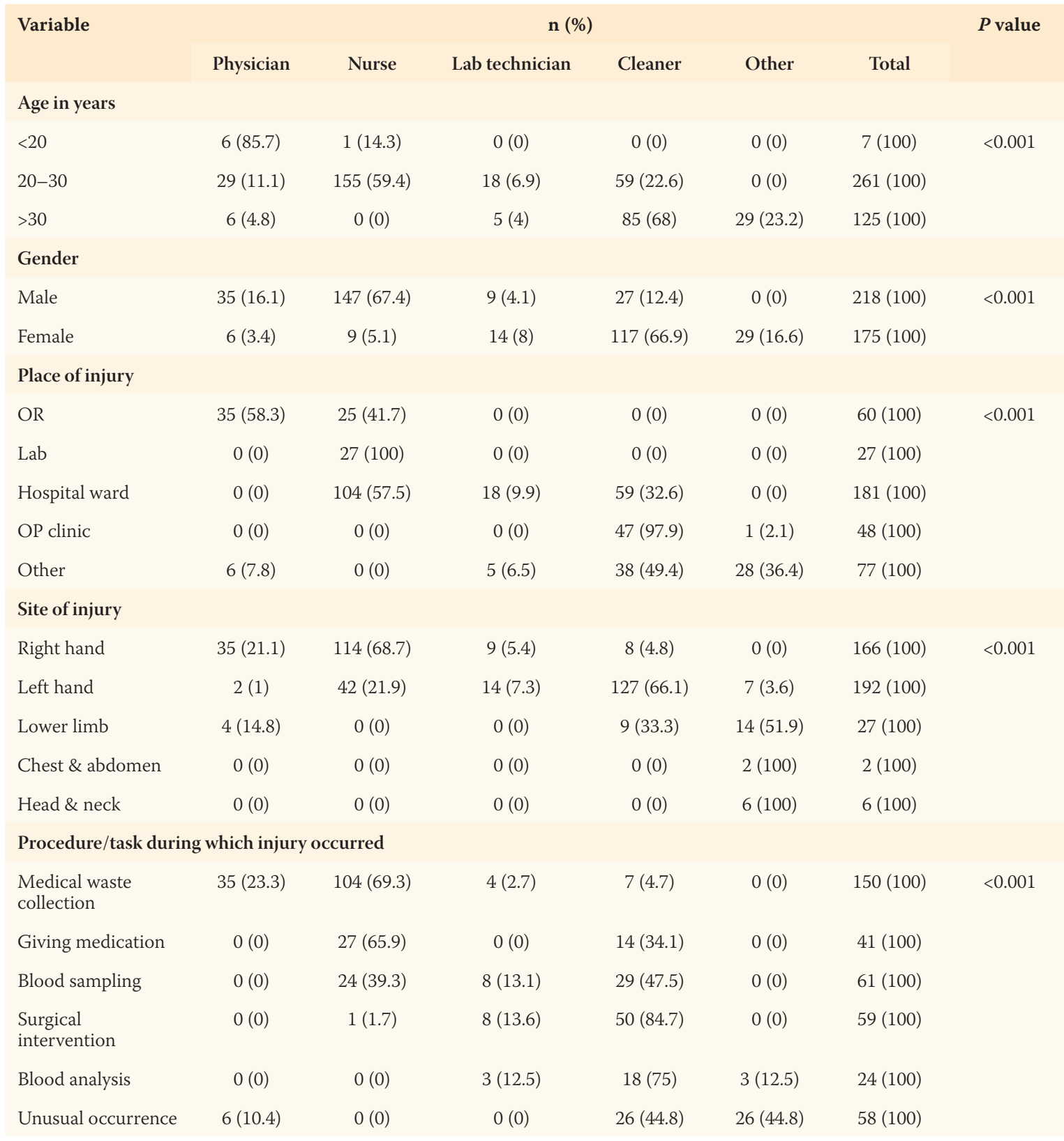

$O R=$ operating room; $O P=$ outpatient

(30.3\%) than other procedures. It is noteworthy that NSSIs among physicians occurred mainly during surgical interventions (85.4\%). During surgical interventions, the left hand was more commonly injured (30.7\%) while the right hand was more commonly injured during medical waste collection (83.1\%) [Table 4].

Regarding the comparison of NSSIs by site to other independent variables, the site of injury was statistically significant for all variables $(P<0.001$ each). In OP clinics, injuries were reported only in the left hand (100\%). Moreover, among cleaners (88.2\%), females (77.7\%) and at hospital wards (56.4\%) left hand injuries were the most common. Among the procedures/tasks during which an injury occurred, the right hand was most often injured during medical waste collection (92\%) [Table 5].

\section{Discussion}

NSSIs are frequent yet preventable occupational hazards among HCWs. According to recent World Health Organization estimates, approximately two million NSSI cases are reported annually, but this number could be an underestimation as many cases of NSSIs are not reported, especially in developing countries. ${ }^{1,11,18}$ Public health sectors are concerned about NSSIs because they comprise a major source of morbidity and mortality worldwide. It is estimated 
Table 3: Comparison of needle stick and sharp injuries by location of injury to independent variables of healthcare workers in Jordan $(\mathrm{N}=393)$

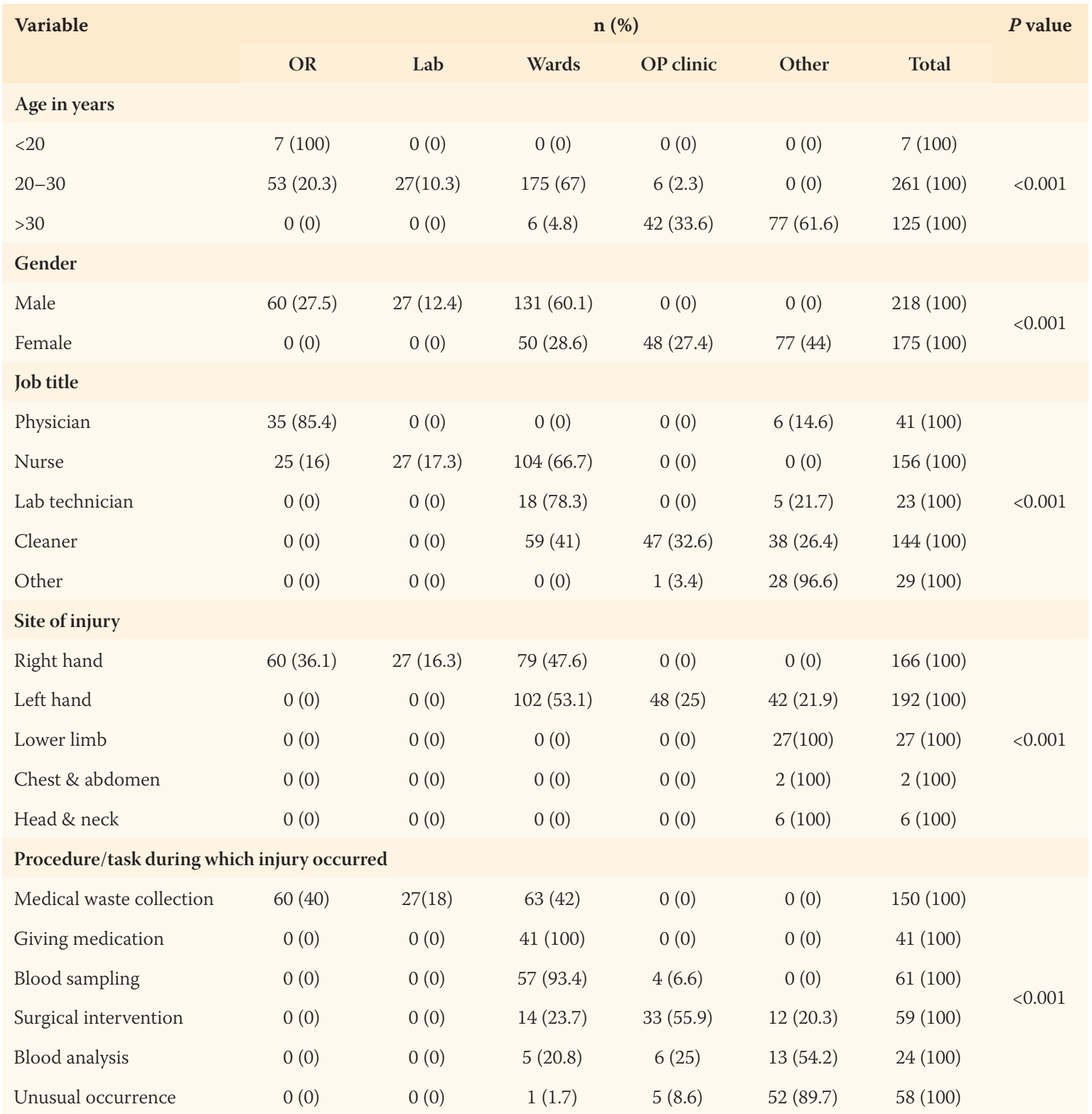

$O R=$ operating room; $L a b=$ laboratory; $O P=$ outpatient .

that NSSIs account for 16,000, 66,000 and 1,000 annual cases of HCV, HBV and HIV infections, respectively. This may lead to approximately 1,100 deaths or significant disabilities. ${ }^{18}$

Despite the global magnitude of NSSI occurrence and the negative impact it has in terms of morbidity and mortality, studies evaluating NSSIs in Jordan are scarce or have not been comprehensive in design or have only focused on the nursing sector. ${ }^{14,16,19-21}$ Although the current study includes only NSSI data from one medical centre, all NSSI reports referred to the Preventive Medicine Department from 2013-2018 were collected, regardless of the referring party. Information related to age, gender and occupation of the NSSI referee were also collected.
Moreover, site of the NSSI and the procedure/ task performed by the individual at the time of injury was acquired. This study helps identify potential risk factors, gaps in the current preventive strategies implemented at KHMC and may serve as a roadmap for future changes in preventive medicine and public health policies at the institution. Although this study was limited in size and only included data collected from one institution, it could serve as a pilot study, and the study design could be easily modified. Implementation on a national scale is a future direction anticipated by the authors.

Analogous to other developing countries, the proportion of NSSIs among HCWs at KHMC was relatively high. ${ }^{4,5,7,13,22-26}$ This finding is in agreement 
Table 4: Comparison of needle stick and sharps injuries by procedure/task during which the injury occurred to independent variables of healthcare workers in Jordan $(\mathrm{N}=393)$

\begin{tabular}{|c|c|c|c|c|c|c|c|c|}
\hline Variable & \multicolumn{7}{|c|}{ n (\%) } & $P$ value \\
\hline \multicolumn{9}{|l|}{ Age in years } \\
\hline$<20$ & 7 (100) & $0(0)$ & $0(0)$ & $0(0)$ & $0(0)$ & $0(0)$ & 7 (100) & \multirow{2}{*}{$<0.001$} \\
\hline$>30$ & $0(0)$ & $2(1.6)$ & $4(3.2)$ & $41(32.8)$ & $20(16)$ & $58(46.4)$ & $125(100)$ & \\
\hline \multicolumn{9}{|l|}{ Gender } \\
\hline Male & $150(68.8)$ & 37 (17) & 25 (11.5) & $6(2.8)$ & $0(0)$ & $0(0)$ & $218(100)$ & $<0.001$ \\
\hline \multicolumn{9}{|l|}{ Job title } \\
\hline Physician & $0(0)$ & $0(0)$ & $0(0)$ & 35 (85.4) & $0(0)$ & $6(14.6)$ & $41(100)$ & \multirow{5}{*}{$<0.001$} \\
\hline Nurse & $104(66.7)$ & $27(17.3)$ & $24(15.4)$ & $1(0.6)$ & $0(0)$ & $0(0)$ & $156(100)$ & \\
\hline Lab technician & $4(17.4)$ & $0(0)$ & $8(34.8)$ & $8(34.8)$ & $3(13)$ & $0(0)$ & $23(100)$ & \\
\hline Cleaner & $7(4.9)$ & $14(9.7)$ & $29(20.1)$ & $50(34.7)$ & $18(12.5)$ & $26(18)$ & $144(100)$ & \\
\hline Other & $0(0)$ & $0(0)$ & $0(0)$ & $0(0)$ & $3(10.3)$ & $26(89.7)$ & $29(100)$ & \\
\hline \multicolumn{9}{|l|}{ Place of injury } \\
\hline OR & $60(100)$ & $0(0)$ & $0(0)$ & $0(0)$ & $0(0)$ & $0(0)$ & $60(100)$ & $<0.001$ \\
\hline \multicolumn{9}{|l|}{ Site of injury } \\
\hline Right hand & $138(83.1)$ & $18(10.8)$ & $10(6)$ & $0(0)$ & $0(0)$ & $0(0)$ & $166(100)$ & \multirow{5}{*}{$<0.001$} \\
\hline Left hand & $12(6.2)$ & $23(12)$ & $51(26.6)$ & $59(30.7)$ & $19(9.9)$ & $28(14.6)$ & $192(100)$ & \\
\hline Lower limb & $0(0)$ & $0(0)$ & $0(0)$ & $0(0)$ & $5(18.5)$ & $22(81.5)$ & $27(100)$ & \\
\hline Chest \& abdomen & $0(0)$ & $0(0)$ & $0(0)$ & $0(0)$ & $0(0)$ & $2(100)$ & $2(100)$ & \\
\hline Head \& neck & $0(0)$ & $0(0)$ & $0(0)$ & $0(0)$ & $0(0)$ & $6(100)$ & $6(100)$ & \\
\hline
\end{tabular}

OR = operating room; $O P=$ outpatient Lab = laboratory.

with the results of many studies that found a high incidence rate of NSSIs among nurses and nursing students. ${ }^{1,15,16,21,23,24,27}$ The exact cause of the high proportion of NSSIs among HCWs, including nurses, is unknown but could be related to several factors. It is possible that the public in Jordan and many other developing countries prefer injections over other methods for the delivery of drugs and pharmaceuticals. ${ }^{11,21}$ This preference would result in a higher rate of injections in public and private clinics; a higher injection rate could explain the high proportion of injection-related NSSIs observed in this study. Hospitals and other medical centres in Jordan, especially those affiliated with the military, are shortstaffed but have a high volume of visitors. ${ }^{14}$ This high HCW-to-patient ratio results in a high workload among hospital staff, including nurses. High workload was previously shown to be associated with increased frequency of occupational injuries among nurses in Jordan. ${ }^{14,16,20,21}$ Indeed, a high incidence of NSSIs appears to be a global problem as studies from many countries around the world have reported similar findings among nurses. ${ }^{4,10,16,21,28-30}$ In this study, a higher proportion of NSSIs was reported among male nurses compared to female nurses. This finding, however, is not in agreement with similar investigations in Jordan, Saudi Arabia, Kenya, Ethiopia and Iran. ${ }^{12,20,22,25,31}$ These studies reported a higher incidence of NSSIs among female nurses compared to male nurses. The difference observed in gender distribution of NSSIs may be attributed to differences in the male-to-female ratio between different hospitals, especially as KHMC has 
Table 5: Comparison of needle stick and sharp injuries by site of injury to independent variables of healthcare workers in Jordan $(\mathrm{N}=393)$

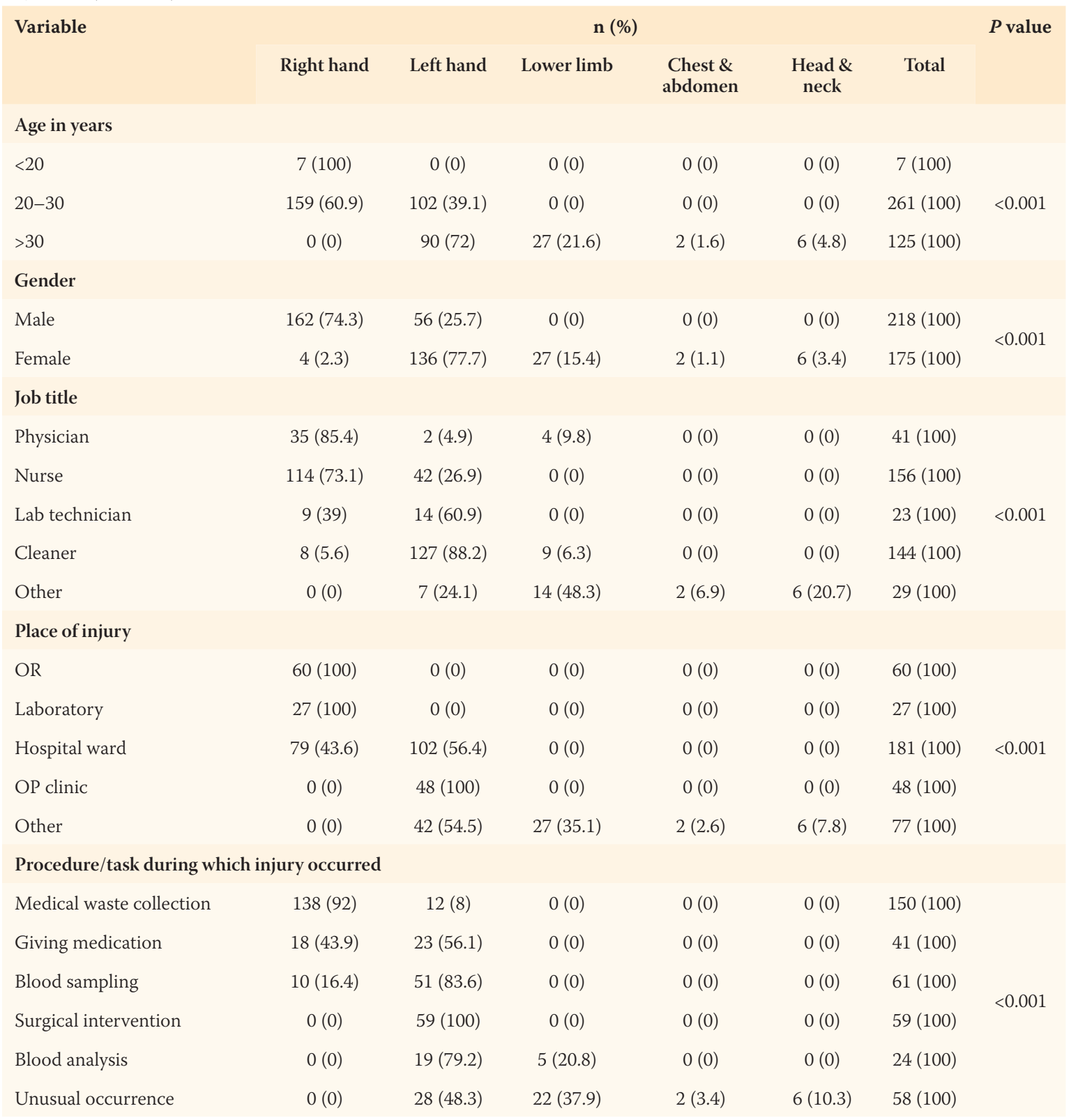

$O R=$ operating room; $O P=$ outpatient.

more male than female nurses, potentially explaining the higher proportion of injuries among males.

The current findings indicate that hospital wards were the most common location at KHMC where NSSIs took place. This result is in agreement with the findings of several other studies. ${ }^{27,32}$ A possible explanation is that this area of the hospital has high foot-traffic as patients enter or leave the ward. Moreover, the ward experiences a high daily volume of procedures that require the use of needles and sharp objects. ${ }^{27,32}$ Such procedures are mainly done by nurses, which may explain the significant association of medical ward injuries with occupation, young age and left-hand injuries, which are typical characteristics for young nurses working in a busy hospital.
These results also demonstrate that most NSSIs at the hospital wards were significantly more often acquired during medical waste collection, more frequent among males, more likely to occur to either nurses or cleaners and significantly more likely to occur in the left hand. A possible explanation for the higher frequency of NSSIs among nurses and cleaners during medical waste collection is that both are involved in disposing needles/syringes, which often requires recapping of the needle. Right-handed individuals usually use their right hand to hold syringes or needles and the left hand for recapping. Most nurses and cleaners responsible for recapping needles are righthanded. ${ }^{24}$ This could explain why the majority of NSSIs were to the left hand. Similarly, several studies have 
reported that recapping was a significant contributor to NSSIs. ${ }^{4,24,33}$

This study highlights the high frequency of NSSIs and indicates that there is a need for proper intervention measures to reduce this preventable source of morbidity and mortality. As NSSIs constitute the largest occupational hazard for HCWs, the findings of this study should impact local and national healthcare settings. This study's findings should encourage institutions, with similar occupational settings that have a high proportion of NSSIs, to revisit their surveillance reporting systems and implement proper educational and training programmes. In addition, since exposure to NSSIs is often associated with blood-borne pathogens, prevention strategies should not be limited to the population of this study but also extend to include all HCWs worldwide.

However, this study had some limitations. The data used was self-reported and therefore only included information from individuals familiar with the impact of NSSIs on the quality of health services and may have only captured those who were wellversed in the importance of reporting NSSIs. This data may not be representative of all NSSI cases that took place within the timeframe set for data collection. The study included data collected from only one healthcare institution in Jordan affiliated with the Royal Medical Services. Findings of this study require confirmation by using data collected from a larger sample size across multiple public and private healthcare institutions in Jordan. Nonetheless, the findings of this study will increase knowledge about the factors associated with the occurrence of the NSSIs and support and contribute to the effort of establishing a national reporting system for NSSIs in Jordan's public healthcare sector; such a system can be easily adapted in other countries as well.

\section{Conclusion}

Despite the limitations of this study, it confirms the findings of previous reports that highlighted the high proportion of NSSIs among HCWs in Jordan. Proper intervention measures, including well-designed training and awareness programmes, should be mandated in all medical institutions in Jordan. The success of these interventions could be applicable to other developing countries as well. Such a programme should incorporate surveillance techniques that enforce implementation of standard precautions that protect HCWs, regardless of their occupation, job title, place of work or sociodemographic characteristics. Although these precautions should be compulsory for all HCWs, additional measures that target high-risk groups, such as nurses and cleaners, should include additional training or awareness prog- rammes to ensure their safety. These training or awareness programmes should focus on the importance of reporting NSSIs, explaining the objectives of surveillance systems, outlining available resources, developing skills to decrease the incidence of NSSIs and building leadership capacity for evaluating programmes and training others in the future.

\section{CONFLICT OF INTEREST}

The authors declare no conflicts of interest.

\section{FUNDING}

No funding was received for this study.

\section{References}

1. Rapiti E, Prüss-Üstün A, Hutin Y. Sharp injuries: Assessing the burden of disease from sharps injuries to health-care workers at national and local levels. From: https://apps.who.int/iris/ handle/10665/43051 Accessed: Aug 2019.

2. Khabour OF, Al Ali KH, Mahallawi WH. Occupational infection and needle stick injury among clinical laboratory workers in AlMadinah city, Saudi Arabia. J Occup Med Toxicol 2018; 13:15. https://doi.org/10.1186/s12995-018-0198-5.

3. Cooke CE, Stephens JM. Clinical, economic, and humanistic burden of needlestick injuries in healthcare workers. Med Devices (Auckl) 2017; 10:225-35. https://doi.org/10.2147/MDER.S140846.

4. Jahangiri M, Rostamabadi A, Hoboubi N, Tadayon N, Soleimani A. Needle stick injuries and their related safety measures among nurses in a university hospital, Shiraz, Iran. Saf Health Work 2016; 7:72-7. https://doi.org/10.1016/j.shaw.2015.07.006.

5. Matsubara C, Sakisaka K, Sychareun V, Phensavanh A, Ali M. Prevalence and risk factors of needle stick and sharp injury among tertiary hospital workers, Vientiane, Lao PDR. J Occup Health 2017; 59:581-5. https://doi.org/10.1539/joh.17-0084-FS.

6. World Health Organization. Protecting healthcare workers from occupational exposure to bloodborne pathogens: The role of WorkSafeBC. From: www.who.int/occupational_health/ publications/newsletter_17_regions/en/index2.html Accessed: Aug 2019.

7. Hanafi MI, Mohamed AM, Kassem MS, Shawki M. Needlestick injuries among health care workers of University of Alexandria hospitals. East Mediterr Health J 2011; 17:26-35. https://doi. org/10.26719/2011.17.1.26

8. Kakizaki M, Ikeda N, Ali M, Enkhtuya B, Tsolmon M, Shibuya K, et al. Needlestick and sharps injuries among health care workers at public tertiary hospitals in an urban community in Mongolia. BMC Res Notes 2011; 4:184. https://doi.org/10.1186/1756-0500-4-184.

9. Singru SA, Banerjee A. Occupational exposure to blood and body fluids among health care workers in a teaching hospital in Mumbai, India. Indian J Community Med 2008; 33:26-30. https://doi.org/10.4103/0970-0218.39239.

10. Al Jarallah AM, Ahmed AS. Risk management approach of needle stick and sharp injuries among nurses, Saudi Arabia: An interventional study. J Arab Soc Med Res 2016; 11:50-5. https://doi.org/10.4103/1687-4293.199300.

11. King KC, Strony R. StatPearls [Internet]. Needlestick. Treasure Island, Florida, USA: StatPearls Publishing LLC, 2019.

12. Mbaisi EM, Ng'ang'a Z, Wanzala P, Omolo J. Prevalence and factors associated with percutaneous injuries and splash exposures among health-care workers in a provincial hospital, Kenya, 2010. Pan Afr Med J 2013; 14:10. https://doi.org/10.11604/ pamj.2013.14.10.1373. 
13. Amini M, Behzadnia MJ, Saboori F, Bahadori M, Ravangard R. Needle-stick injuries among healthcare workers in a teaching hospital. Trauma Mon 2015; 20:e18829. https://doi.org/10.58 12/traumamon.18829.

14. Abozead SE, Abuhasheesh M, Nawafleh HA, Kawafha MM, Tarawneh O. Knowledge and practices of Jordanian nurses on needlestick injuries. Infec Dis Clin Pract 2015; 23:21-5. https://doi.org/10.1097/IPC.0000000000000159.

15. Ghasemi M, Khabazkhoob M, Hashemi H, Yekta A, Nabovati P. The incidence of needle stick and sharp injuries and their associations with visual function among hospital nurses. J Curr Ophthalmol 2017; 29:214-20. https://doi.org/10.1016/j. joco.2017.06.001.

16. Suliman M, Al Qadire M, Alazzam M, Aloush S, Alsaraireh A, Alsaraireh FA. Students nurses' knowledge and prevalence of needle stick injury in Jordan. Nurse Educ Today 2018; 60:23-7. https://doi.org/10.1016/j.nedt.2017.09.015.

17. Nawafleh HA, Abozead SE, Al Momani MM, Aaraj H. Investigating needle stick injuries: Incidence, knowledge and perception among South Jordanian nursing students. J Nurs Educ Prac 2018; 8:59-69. https://doi.org/10.5430/jnep.v8n4p59.

18. Goniewicz M, Włoszczak-Szubzda A, Niemcewicz M, Witt M, Marciniak-Niemcewicz A, Jarosz MJ. Injuries caused by sharp instruments among healthcare workers--International and Polish perspectives. Ann Agric Environ Med 2012; 19:523-7.

19. Khuri-Bulos NA, Toukan A, Mahafzah A, Al Adham M, Faori I, Abu Khader I, et al. Epidemiology of needlestick and sharp injuries at a university hospital in a developing country: A 3-year prospective study at the Jordan University Hospital, 1993 through 1995. Am J Infect Control 1997; 25:322-9. https://doi. org/10.1016/s0196-6553(97)90024-9.

20. Hassan Z, Wahsheh M. Occupational exposure to sharp injuries among Jordanian health care workers. Infect Dis Clin Pract 2009; 17:169-74. https://doi.org/10.1097/IPC.0b013e31819b8d10.

21. Khraisat FS, Juni MH, Said SM, Abd Rahman A, HamdanMansour A. Needle stick injuries prevalence among nurses in Jordanian hospitals. Int J Public Health Clin Sci 2015; 2:7-16.

22. Jahan S. Epidemiology of needlestick injuries among health care workers in a secondary care hospital in Saudi Arabia. Ann Saudi Med 2005; 25:233-8. https://doi.org/10.5144/02564947.2005.233.

23. Rampal L, Zakaria R, Sook LW, Zain AM. Needle stick and sharps injuries and factors associated among health care workers in a Malaysian hospital. Eur J Soc Sci 2010; 13:354-62.
24. Askarian M, Malekmakan L, Memish ZA, Assadian O. Prevalence of needle stick injuries among dental, nursing and midwifery students in Shiraz, Iran. GMS Krankenhhyg Interdiszip 2012; 7:Doc05. https://doi.org/10.3205/dgkh000189.

25. Bekele T, Gebremariam A, Kaso M, Ahmed K. Factors associated with occupational needle stick and sharps injuries among hospital healthcare workers in Bale Zone, Southeast Ethiopia. PLoS One 2015; 10:e0140382. https://doi.org/10.1371/ journal.pone.0140382.

26. Khabour OF, Al Ali KH, Mahallawi WH. Occupational infection and needle stick injury among clinical laboratory workers in AlMadinah city, Saudi Arabia. J Occup Med Toxicol 2018; 13:15. https://doi.org/10.1186/s12995-018-0198-5.

27. Abdifard E, Sepahvand E, Aghaei A, Hosseini S, Khachian A. Needle-stick, sharp injuries, and its related factors among nurses of Imam Reza Hospital, Kermanshah, Iran. J ClientCentered Nurs Care 2015; 1:183-8. https://doi.org/10.15412/J. JCCNC.04010403.

28. Kebede A, Gerensea H. Prevalence of needle stick injury and its associated factors among nurses working in public hospitals of Dessie town, Northeast Ethiopia, 2016. BMC Res Notes 2018; 11:413. https://doi.org/10.1186/s13104-018-3529-9.

29. Trinkoff AM, Le R, Geiger-Brown J, Lipscomb J. Work schedule, needle use, and needlestick injuries among registered nurses. Infec Control Hosp Epidemiol 2015; 28:156-64. https:// doi.org/10.1086/510785.

30. Smith DR, Mihashi M, Adachi Y, Nakashima Y, Ishitake T. Epidemiology of needlestick and sharps injuries among nurses in a Japanese teaching hospital. J Hosp Infect 2006;6 4:44-9. https://doi.org/10.1016/j.jhin.2006.03.021.

31. Razieh L, Gashtasbi A. Needle stick and sharps injuries and its risk factors among health center personnel (Astara; Iran, 2006). J Babol Univ Med Sci 2008; 10:71-7.

32. Shanks NJ, al-Kalai D. Occupation risk of needlestick injuries among health care personnel in Saudi Arabia. J Hosp Infect 1995; 29:221-6. https://doi.org/10.1016/0195-6701(95)90332-1.

33. Motaarefi H, Mahmoudi H, Mohammadi E, Hasanpour-Dehkordi A. Factors associated with needlestick injuries in health care occupations: A systematic review. J Clin Diagn Res 2016; 10:IE1-4. https://doi.org/10.7860/JCDR/2016/17973.8221. 